\title{
QUALIDADE DO PRODUTO \\ E DOS SERVIÇOS \\ Fator Decisivo no Mercado \\ de Turismo
}

\author{
Mario Carlos Beni*
}

\begin{abstract}
RESUMO: O produto final do Sistema de Turismo, resultante do somatório de recursos e serviços deve otimizar sua qualidade para concorrer com êxito num mercado extremamente exigente e competitivo.
\end{abstract}

UNITERMOS: Turismo: mercado: qualidade do produto-serviço. Produto turístico: qualidade.

ABSTRACT: The final product of the tourisme system resulting fiom the complex of resources and senvices shall raise its standard to compete sucessfully in an extremely' dernanding and competitive market.

KEY WORDS: Tourisin: market: satandard of the product-sen'ice. Tourist product: standard.

\section{PROMOÇÃO, PRODUTOS E RECURSOS}

A promoção, moderno e valioso instrumento para a venda de qualquer produto e/ou serviço, tornou-se elemento imprescindível de penetração no mercado tanto para o Turismo como conjunto de bens e serviços, como também para os subprodutos que o compõem. A sua eficácia relaciona-se, diretamente, com a composição do produlo, que é a estrutura de base da imagem que se deseja transmitir para despertar a atenção do consumidor, e é entendida como resultado de um fluxo constante, portanto ininterrupto, de relaçōes entre quem produz e quem consome, entre o produto e quem pode comprá-lo.

(*) Livre-Docente pela ECA/USP e Professor Associado do Departamento de Relaçōes Públicas. Propaganda e Turismo da ECAMSP. Vice-presidente da AMFORT - Associaçāo Mundial para a Formação Profissional Turística.

End. para corresp.: Rua Bela Cintra. 2060 - apto. 2A - 01415 - São Paulo - SP Brasil. 
Trata-se de um processo a ser planejado em bases científicas que, rompendo com o epirismo atávico e a tradicional improvisação, deriva da idéia à "composição" para a oferta do produto através de ações e estratégias adequadas. Em outros termos, trata-se de criar um produto que venda. Esta é a primeira e mais delicada operação, que corresponde ao moderno imperativo de produzir apenas aquilo que se vende, revolucionando o postulado do passado que obrigava a vender aquilo que se produzia. As outras operações prosseguem através da promoção e da comercialização, utilizando os canais adequados de distribuição, até alcançar o controle do consumo no que concerne à satisfação da demanda, a fim de realizar eventuais correções da oferta para que a imagem do produto mantenha os níveis de qualidade fundamentais de seu poder de atração.

\section{QUALIDADE DO PRODUTO-SERVIÇO TURÍSTICO NO MERCADO}

\subsection{Estrutura Básica do Produto-Serviço}

A estrutura básica do produto-serviço turístico é o território, entendido como a totalidade do ambiente natural e dos espaços adaptados pelo homem.

É pois sobre os recursos naturais e sobre os humanos ('históricos' e culturais) que é necessário empenhar-se para favorecer o turismo, como um conjunto de atrativos sobre o qual se constrói o produto, do qual depende principalmente a sua imagem, aquela que promove a firmação no mercado, por conseguinte, a venda e o consumo.

É essa a matéria-prima que constitui a premissa da qualidade e da própria vida do produto como conjunto, base sobre a qual se incluem e se inserem os subprodutos que comporão e conferirão totalidade do sistema de turismo como produto-serviço ofertado.

É importante esclarecer o consumidor (não somente o estrangeiro mas também o doméstico), no sentido de que o território destinado à demanda turística manterá inalteradas no tempo as suas características (os seus recursos) que constituem um bem, mas que infelizmente acha-se em posição dicotômica: é simultaneamente um bem de produção e um bem de consumo. Bem de produção para a população local e bem de consumo para a demanda externa. Seu consumo ordenado, com relação à sua capacidade limite para evitar a degradação física e sócio-cultural e, portanto, a destruição, deve ser garantida pela "marca"; pelos seus responsáveis, públicos e privados, a fim de impedir que o turismo perca o prestígio e se anule como área de atração.
A referência é a qualidade do produto que perde em competitividade, pois sua degradação é notória, tangível: nos museus fechados, nos transportes insuficientes, nos aeroportos congestionados, na classificação hoteleira indecifrável, na poluição do ar, no "couvert" mais serviços dos restaurantes, nos horários dos bancos, na insegurança, na dúbia assistência médica, na sinalização incompreensível, na inexistência de estacionamentos, nas informações teóricas etc. Assim, muitas vezes as tentativas para reatar as relações com o mercado resultam, conseqüentemente, mais em tentativas de emergência que em intervenções sobre as causas da degradação.

É uma profunda operação aquela que se impõe. Uma intervenção sobre as causas a fim de reconstruir. Uma ação que deve envolver todos, o público principalmente, se o turismo, como se afirma, interessa não a uma região mas ao País como um todo, porquanto elemento propulsor da economia.

\subsection{Oferta}

A oferta receptiva, último elo da corrente do produto turístico, que mais encontra a aceitação e apreciação da clientela é aquela que se expressa por bons modelos qualitativos através de gestões altamente profissionais. Por exemplo, o Organismo de Turismo, a nível regional, tem de ser chamado a fazer corresponder as adaptações - técnicas e de gestão -, indispensáveis para alinhar a oferta aos modelos de turismo internacionais, se quiser que o produto ocupe uma posição forte no mercado. Isto significa uma vigilância atenta e constante para que a relação qualidade/preço dos serviços ofertados seja válida, isto é, justa e competitiva; não um reflexo somente aparente da classificação atribuída ao estabelecimento, com a improvisação até agora observada.

Uma outra questão envolve a cultura empresarial que deve ser difundida em todos os estabelecimentos que estão em contato com o consumidor, independentemente de sua classificação. Às diversas classificações atribuídas deve corresponder uma qualidade de serviço certa, senão a imagem refletirá no mercado a não-qualidade do produto.

\subsection{Demanda}

A fruição do produto turístico é condicionada por fatores externos e, muitas vezes, por excessivas generalizações dos aspectos negativos da imagem turística do produto, seja local ou regional, seja nacional, em especial no estrangeiro. Mas quando uma imagem apresenta aspectos negativos, as generalizações, no que tange ao produto turismo, acabam por ser naturalmente excessivas, principalmente quando 
provêm de consumidores distantes. Então torna-se imperativo recompor o produto, reestruturar os canais de distribuição no País e no exterior, quando se quer firmar uma imagem nova. Senão os fluxos de turismo receptivo continuarão a ser não muito expressivos, o que, traduzido em termos estatísticos e contábeis, equivale a negativo.

A redução dos fluxos individuais representa o estágio de degradação da imagem. E a demanda em todos os lugares de destinação turística apresenta uma sempre mais elevada sensibilidade e atenção à qualidade das permanências e, em especial, à qualidade do ambiente. E é sobre esta qualidade que o consumidor deseja estar seguro, através de uma informação correta e atual.

\subsection{Ação Estatal}

As linhas de direção e os objetivos da ação estatal deveriam estar inseridos em um programa sério e ambicioso, considerando a realidade e quanto a oferta necessita para alinhar-se à melhor concorrência no mercado. Entretanto, a ação isolada, como a que vem sendo realizada a nível regional, sem a ação complementar de outros setores e órgãos, públicos e privados, torna-se inútil, danificando e degradando a própria imagem do produto-serviço turístico. São planos parciais que tornam-se contraproducentes, face à ausência de uma Política Nacional de Turismo.

Para que esse quadro se reverta, o Organismo Nacional de Turismo, a nível regional, deveria atentar para as linhas de direção e os objetivos descritos a seguir.

\subsubsection{Linhas de Direção}

a) Valorizar os aspectos ambientais da oferta turística.

b) Melhorar a capacidade receptiva através de uma ação energética dos órgãos locais e da nova organização turística.

c) Melhorar a informação, direcionando-a mais para as diferentes exigências de uma demanda segmentada segundo diferentes motivaçōes.

d) Instar os operadores a estrutrarem-se em consórcios de promoção.

e) Sustentar a ação de comercialização conduzida por pessoas para habilitados.
2.4.2 Objetivos

a) Aumento dos fluxos sazonais, enfatizando particularmente os segmentos da "terceira idade" e "juvenil-estudantil".

b) Recuperação, possivelmente para o verão, dos fluxos receptivos internacionais motivados pelas condições climáticas em geral.

c) Desenvolvimento de uma maior fruição da oferta congressual por parte dos fluxos receptivos nacionais e internacionais.

d) Recuperação dos fluxos receptivos internacionais individuais.

\section{QUALIDADE COMO ESTRATÉGIA}

A qualidade que paga ou compensa é certamente a fórmula usada e muito abusada, empregada mais para safisfazer uma exigência pessoal própria que para responder a uma necessidade de avaliação objetiva da correlação com o preço pago em troca daquela qualidade. É, porém, um "modo de ser" do produto ou do serviço, intangível e portanto subjetivo, diferente do ponto de vista de quem a oferta e de quem a consome.

No que tange ao assunto turismo, como conjunto de produtos e serviços, e aos setores de hotelaria e de alimentação como pontos terminais da oferta, onde é mais imediato o contato com o consumidor, a qualidade refere-se antes ao serviço que, como aquela, tem a característica de ser intangível, ainda que, possa ser mensurável.

Nesse caso, a qualidade se manifesta simultaneamente ao serviço, e, por isso, a produtividade relativa (que em geral se mede pelas vendas) se expressa somente em termos da satisfação real do cliente. E é da taxa de satisfação deste que o mercado recebe a imagem símbolo do produto-serviço, ou seja, a taxa de fidelidade.

Portanto, o serviço completa e caracteriza a qualidade da produção. Mas, no caso do turismo a qualidade se alicerça no comportamento do homem, ao qual é confiada a responsabilidade pelo serviço. É neste, ou no local onde tal serviço é prestado, que aumenta o risco de não serem correspondidas as expectativas da demanda, que tem uma idéia própria da qualidade do serviço, com relação não somente às promessas da publicidade, mas também às exigências e motivações próprias que espera ser satisfatórias. 
Por isso, o produtor (fornecedor do produto-serviço turístico), mais que ao nível de qualidade estabelecido pela própria empresa, deve ter como referência a imaginação e a criatividade para poder atender às expectativas do cliente. Ter uma idéia clara significa individualizar a própria clientela, ou o próprio segmento da demanda com necessidades e motivações bem definidas, às quais deve satisfazer com um determinado produto (e somente aquele produto), feito para aquele consumidor. Pensar em satisfazer a todos significa condenar-se ao fracasso. Sob o ponto de vista funcional, o quarto de um hotel é igual ao quarto de outro hotel; a mesa de um restaurante é igual à mesa de outro restaurante; mas a qualidade dos serviços ofertados é que constitui a diferença.

A busca pela qualidade por parte da oferta, isenta ou livre das "matérias-primas" empregadas, só pode ser encontrada no empenho no serviço, isto é, nos homens. Em termos da atividade ou trabalho do empresário, isso quer dizer ter sempre em mente e em discussão tal empenho. Idear o que se pode fazer de novo e de melhor para satisfazer as exigências da clientela, prevendo para onde esta se dirige na composição do produto-serviço.

Isto significa formação e qualificação empresarial. Sem formação, sem cultura empresarial, não se é capaz sequer de tornar-se concorrente de si mesmo (do próprio produto como se fosse de outros), e com isso responder-se à demanda com a pergunta: por que o cliente deve preferir o meu produto e não o de outros?

Se tudo isso é válido para um subproduto, é mais válido ainda para um "produto-conjunto", pois o produto brasileiro encontra similar do outro lado do oceano (Caribe). É preciso diversificá-lo quanto à qualidade, aos serviços e aos recursos humanos, porquanto não se pode improvisar o grau de expectativa e o nível de satisfação da clientela. Isso requer previsão, organização, coordenação e capacidade de controle para os ajustamentos e adaptações que se impõem frente às sempre novas exigências do mercado, mais Jo que nunca agressivo e insistente, condições estas que só podem ser adquiridas com a formação, com a especialização, pois se faltarem ao empresário, é a falência do negócio; se faltarem no setor público, é o declínio da imagem, a perda de competitividade do País como destinação turística.

Deve-se construir ou reconstruir para ter ou reaver uma imagem global que compreenda uma qualidade certa, particular dos diversos componentes: a qualidade dos diferentes produtos e serviços que se destinam ao consumidor, bem conscientes de que a todo preço deve corresponder um determinado serviço-produto. É na razão preço/produto que se encontram os diversos níveis de qualidade, porque a esta não deve e não pode ser considerada um luxo, um artigo opcional.

\section{CONSIDERAÇÕES FINAIS}

Sem qualidade do serviço turístico não há concorrência possível no mercado, nem pelas empresas, nem pelos Estados. Impõe-se mudar o rumo da concorrência, porque não é o preço o fator que pode ditar a concorrência, mas sim os recursos humanos adequadamente preparados.

É necessária uma reforma que, de acordo com as necessidades do setor e a evolução da atividade de turismo no mundo e no País, permita uma oferta de educação atualizada que melhore os cursos de turismo (níveis técnico e superior) e facilite a incorporação dos profissionais no mercado de trabalho.

O turismo necessita de profissionais cada vez melhor preparados. Para orientar adequadamente sua formação e preparo deve-se estabelecer uma estreita colaboração entre as Escolas e as Empresas, as quais terão condições de absorver os futuros profissionais. Além disso, o desafio comercial deverá levar em consideração a nova dimensão do mundo, a evolução da demanda e a concorrência internacional. Mas o verdadeiro desafio comercial está na realização qualidade/preço, quer dizer, a vontade de ofertar uma maior qualidade.

As chaves do êxito compreenderão três ingredientes:

a) inovação: criatividade, imaginação e questionamento;

b) desempenho, produtividade, satisfação de alcançar um objetivo;

c) qualidade, profissionalismo, busca permanente da satisfação do cliente.

Estes três elementos são interativos:

$$
\begin{aligned}
& \text { Nào há desempenho sem qualidade e sem inor'açào. } \\
& \text { Nào há qualidade sem desempenho e sem inov'açăo. } \\
& \text { Não há inovação sem qualidade e sem desempenho. } \\
& \hline
\end{aligned}
$$

O futuro do turismo depende, fundamentalmente, da qualidade dos serviços, e a qualidade destes depende dos recursos humanos, hasicamente de sua formação.

\section{BIBLIOGRAFIA}

1. OCONNOR E.W. Marketing in tourism resources. In: Tourism mancgemen book London, World Travel. 1989, p. 216-23.

2. PUDDU. L. G. Turismo in Liguria. Revista del Albergo. Milano. Bocconi. 1990

3. WATSON. A. Marketing in tourism. Annals of tourism research. Wiscosim, 1: 6, n. +. p. $469-72,1979$ 